Article

\title{
The Effect of Seaweed Glue in the Separation of Copper-Molybdenum Sulphide Ore by Flotation
}

\author{
Zhixiang Chen ${ }^{1}$, Guohua Gu ${ }^{1, *}$, Shuangke $\mathrm{Li}^{1, *}$, Chongqing Wang ${ }^{2}$ and Renfeng Zhu ${ }^{1,3}$ \\ 1 School of Minerals Processing and Bio-Engineering, Central South University, Changsha 410083, China; \\ chenzhixiang93@163.com (Z.C.); zhurf1998@163.com (R.Z.) \\ 2 School of Chemical Engineering and Energy, Zhengzhou University, Zhengzhou 450001, China; \\ zilangwang@126.com \\ 3 Zhaojin Mining Industry Company Limited, Yantai 264000, China \\ * Correspondence: guguohua@126.com (G.G.); 165612115@csu.edu.cn (S.L.)
}

Received: 12 December 2017; Accepted: 22 January 2018; Published: 25 January 2018

\begin{abstract}
Flotation separation of chalcopyrite from molybdenite was studied using seaweed glue (SEG) as a depressant. Flotation process and mechanism were examined by response surface methodology, flotation tests, adsorption tests, zeta potential measurements and fourier transform infrared (FT-IR) spectra. Response surface methodology with a Box-Behnken design suggested the optimal reagent schedule: $\mathrm{pH}$ 4, depressant seaweed glue $197 \mathrm{mg} / \mathrm{L}$, collector amyl xanthate $16 \mathrm{mg} / \mathrm{L}$ and frother (methyl isobutyl carbinol) $20 \mathrm{mg} / \mathrm{L}$, and selective separation of chalcopyrite and molybdenite was achieved by flotation. Comparison of SEG and traditional depressants indicated that the SEG could achieve a similar separation efficiency, and exhibited the advantages of environmental compatibility and economic adaptability. Co-adsorption of seaweed glue and amyl xanthate occurred on the surface of molybdenite, and is explained to happen through distinct mechanisms due to the heterogeneous nature of the surface. It is likely that seaweed glue depresses molybdenite by covering the dixanthogen resulting from adsorption of xanthate ions. It is shown that seaweed glue is as effective a depressant of $\mathrm{Cu}$ /Mo separation as cyanide.
\end{abstract}

Keywords: chalcopyrite; molybdenite; flotation depressant; seaweed glue

\section{Introduction}

In the case of copper-molybdenum separation, chalcopyrite $\left(\mathrm{CuFe}_{2}\right)$ and molybdenite $\left(\mathrm{MoS}_{2}\right)$ are the main copper and molybdenum minerals found in complex sulfide ores. The natural hydrophobicity of molybdenite results from its layered crystal structure. In the case of chalcopyrite, once the mineral is rendered hydrophobic by a xanthate collector, its depression can be effectively achieved by rather drastic chemical treatments [1]. The separation of both hydrophobic chalcopyrite and molybdenite represents a major problem in the treatment of copper-molybdenum sulfide ore. Both of them easily lead to flotation concentrates, thus reducing concentrate grade and causing downstream processing problems as well as increased smelting costs [2]. The separation of chalcopyrite and molybdenite has therefore been the focus of a great deal of research.

The selective separation of sulfide minerals by froth flotation frequently relies on the use of various appropriate depressants that affect the floatability of individual ore components. At present, inorganic depressants are routinely used as the selective depressants. For example, sodium hydro-sulfide (NaHS), Noke's reagent (thiophosphorus or thioarsenic compounds), or even cyanides, are widely used to depress the copper sulfide minerals while molybdenum sulfides are floated [3-7]. However, many problems in the application are inevitable, such as the high dosage and toxicity to the environment. It is necessary to replace these highly toxic reagents with more environmentally friendly chemicals. Therefore, the separation of copper-molybdenum is still a big problem [8,9]. 
Historically, the choice of depressants in flotation has always been based on empirical testing. The trend in recent years has been to focus on special polymers for this purpose [10-12]. The key point is the selection of the distinctive functional group and molecular weight to ensure that the polymer acts appropriately by imparting the correct surface properties on the particular gangue mineral (e.g., inclusion of hydroxyl groups in the polymer to impart hydrophilicity) [13]. Motivated by such requirements, seaweed glue-a non-toxic natural polymer-was tested in this study as a potential depressant in the differential flotation separation of $\mathrm{Cu}$-Mo sulfides.

Sodium alginate (SAG) is one of the special polymers mentioned above, and SAG mainly includes: red algae, green algae, seaweed glue, brown algae, etc. [14]. Seaweed glue (SEG) is a kind of polysaccharide carbohydrate extracted from kelp or sargassum, appearing as white or light-yellow powder. It is easy to dissolve in water and is non-toxic. SEG, also known as kelp glue, is a kind of alginate derivative with linear polymers composed of $\beta$-D-mannuronic acid and $\alpha$-L-guluronic acid [15-18]. The SEG can agglomerate into clumps associated with a few metal ions and ultimately precipitate in water [19]. The structural formula of seaweed glue is shown in Figure 1. The application of SEG as a flotation depressant-both in the laboratory and in commercial processes-has not been reported up to now.

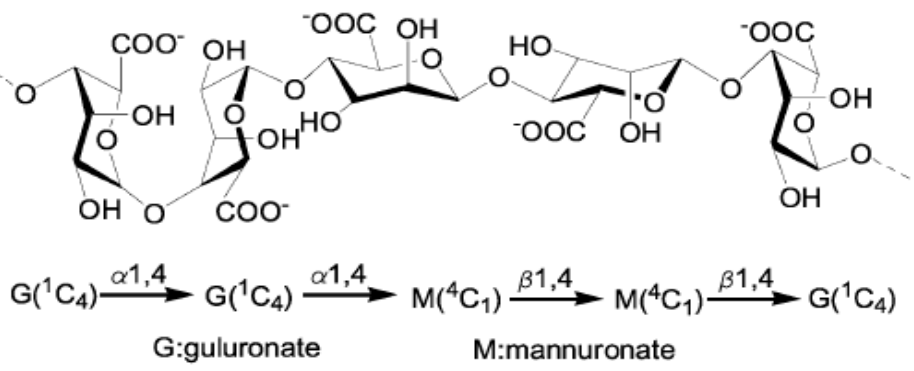

Figure 1. Seaweed glue molecular structure (monomer subunits, G—polyguluronic, M-polymannuronate) [20]. Reproduced with permission from Treenate et al., In vitro drug release profiles of $\mathrm{pH}$-sensitive hydro-xyethylacryl chitosan/sodium alginate hydrogels using paracetamol as a soluble model drug; published by Elsevier, 2017.

The aim of this study was to test SEG as an alternative non-toxic depressant for the separation of chalcopyrite from molybdenite. The effects of variables including initial $\mathrm{pH}$, depressant dosage, and collector dosage on the separation efficiency were evaluated by response surface methodology with a Box-Behnken design. The depression mechanism of SEG on both chalcopyrite and molybdenite was investigated by adsorption tests and zeta potential measurements as well as Fourier transform infrared (FT-IR) spectra.

\section{Materials and Methods}

\subsection{Materials}

Pure chalcopyrite and molybdenite samples were all obtained from Anhui Mining Corporation, China. XRD results of the pure minerals are shown in Figure 2. According to chemical analysis and XRD results, the purity of chalcopyrite was $94.6 \%$ and the purity of molybdenite was $99.5 \%$. Hand-selected crystals of these minerals were crushed to $-1 \mathrm{~mm}$ by a laboratory roll crusher. The crushed products were then ground in a ceramic ball mill and dry-sieved to obtain the $-75+38 \mu \mathrm{m}$-size fractions for micro-flotation tests ( $0.37 \mathrm{~kW}$ operating power and per $2 \mathrm{~min}$ as grinding frequency). A size fraction of $-38 \mu \mathrm{m}$ particles was further ground to $-2 \mu \mathrm{m}$ for adsorption and zeta potential measurements as well as FT-IR studies. Pure mineral samples were stored in a vacuum-desiccator after preparation and washed in an ultrasonic bath for 5 min to remove potential oxidation film before each use. Atmospheric oxidation of chalcopyrite (ageing) produces compounds such as iron-oxyhydroxides 
and basic iron-sulphates on the chalcopyrite surface [21,22]. The oxidation of molybdenite mainly occurred in the defect point of the cleavage surface, and produced compounds like $\mathrm{MoO}_{3}$ [23].

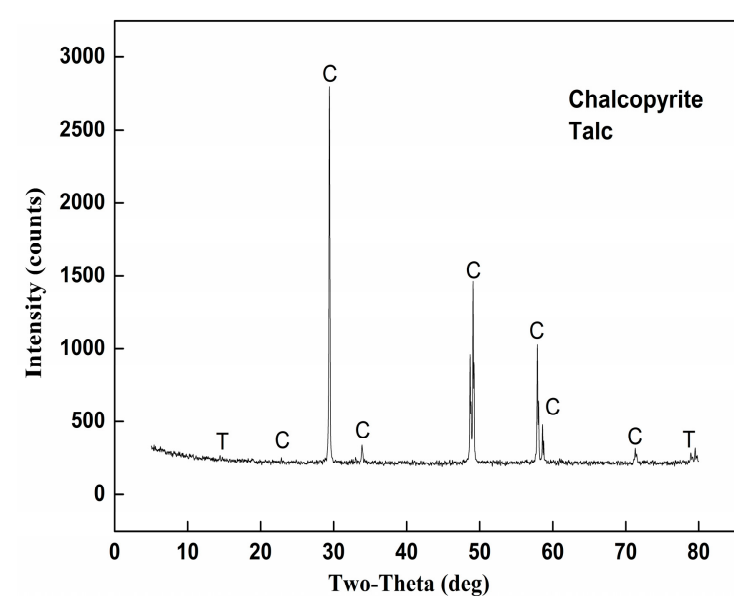

(a)

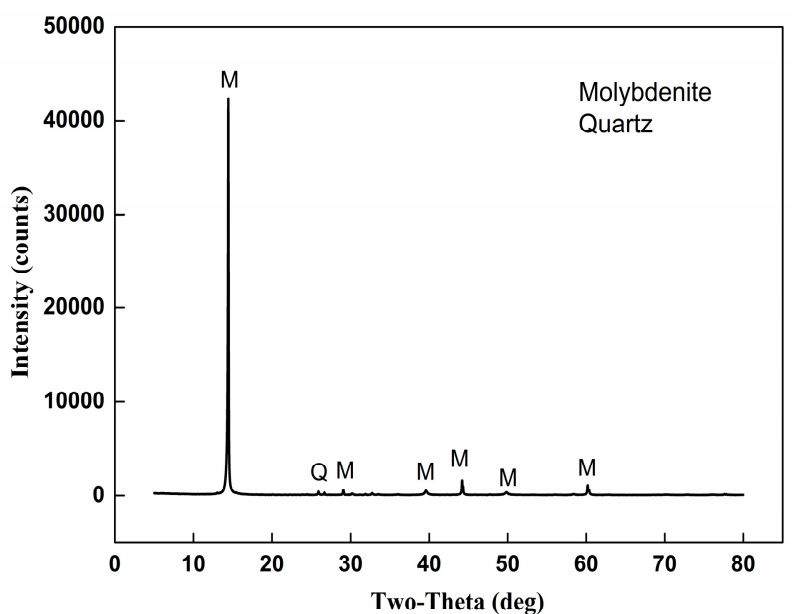

(b)

Figure 2. XRD spectra of pure (a) chalcopyrite and (b) molybdenite for flotation tests.

The anionic depressant seaweed glue (SEG, MW 32,000-200,000, the viscosity of solutions of $1 \%$ SEG (by weight) was 1000-1500 $\mathrm{mPa} \cdot \mathrm{s}$ ) was supplied independently by the IMUMR Flotation Reagents Limited Company, Shandong, China. SEG solutions were prepared by dispersing a known weight of SEG (the molecular formula of the SEG is $\left(\mathrm{C}_{6} \mathrm{H}_{5} \mathrm{O}_{6}\right)_{\mathrm{m}} \cdot\left(\mathrm{C}_{12} \mathrm{H}_{10} \mathrm{O}_{9}\right)_{\mathrm{n}},>92 \%$ purity) in distilled water. The solution was made up to the required volume by adding distilled water and left to equilibrate overnight. Fresh solutions were prepared every three days. Other flotation reagents were amyl xanthate as collector and frother methyl isobutyl carbinol (MIBC), respectively. In addition, the preparation of depressant disodium carboxymethyl-trithiocarbonate (DCMT) was carried out according to the literature [5]. P-Nokes reagents (PNs) were prepared by mixing phosphorus pentasulphide with sodium hydroxide in a mass ratio of 1:1.3 [7,24]. All of the chemicals used for the preparation of depressants were purchased from the local supplier (Guoyao, Changsha, China) without further purification. Hydrochloric acid $(\mathrm{HCl})$ and sodium hydroxide $(\mathrm{NaOH})$ were used to regulate the pulp $\mathrm{pH}$. All of the reagents used in the tests were of analytical grade. Deionized water was used in all tests.

\subsection{Response Surface Methodology}

In this experiment, a three-factor, three-level factorial Box-Behnken design (BBD) was used to model and optimize the mineral separation efficiency. The initial $\mathrm{pH}\left(\mathrm{X}_{1}\right)$, dosage of depressant $\left(X_{2}, \mathrm{mg} / \mathrm{L}\right)$, and dosage of collector $\left(X_{3}, \mathrm{mg} / \mathrm{L}\right)$ were chosen as the three independent variables. The three independent variables in actual values and corresponding coded values (assign value by the software of Box-Behnken design) are listed in Table 1. All of the results received according to BBD experimental runs were analyzed by means of the least-squares regression method for predicting the process response and estimating the coefficients on the basis of the following second-order Equation (1). The equation was used to describe the mathematical relationship between the predicted response $(Y)$ and input variables $\left(X_{1}, X_{2}\right.$, and $\left.X_{3}\right)$ in coded values:

$$
Y=\beta_{0}+\Sigma \beta_{i} X_{i}+\Sigma \beta_{i i} X_{i}^{2}+\Sigma \beta_{i j} X_{i j}
$$

where $Y$ refers to the predicted response of separation efficiency associated with each factor level combination by the model; $\beta_{0}$ is the model constant (intercept term); and $\beta_{i}, \beta_{i i}$, and $\beta_{i j}$ are the linear, quadratic, and interaction coefficients, respectively. Based on the early exploration experiments, the 
optimum range of each independent variable was determined: $\mathrm{pH}$ (3-6), SEG 50-300 mg/L, amyl xanthate $(A X) 10-100 \mathrm{mg} / \mathrm{L}$. In order to better explore the relationship between inhibitors and minerals under strong alkaline conditions, the experimental $\mathrm{pH}$ values of 3-12 were used in this research.

The experimental data was analyzed via Design Expert Software version 8.0.6 (STAT-EASE Inc., Minneapolis, MN, USA) for the analysis of variance (ANOVA) and to assess the goodness of fit of the model.

Table 1. Experimental range and levels of the independent variables. SEG: seaweed glue.

\begin{tabular}{ccccc}
\hline \multirow{2}{*}{ Independent Variables } & \multirow{4}{*}{ Codes } & \multicolumn{4}{c}{ Ranges and Levels } \\
\cline { 3 - 5 } & & $\mathbf{- 1}$ & $\mathbf{0}$ & $\mathbf{1}$ \\
\hline Initial $\mathrm{pH}$ & $X_{1}$ & 3 & 50 & 10 \\
SEG dosage $(\mathrm{mg} / \mathrm{L})$ & $X_{2}$ & 7.5 & 175 & 55 \\
AX dosage $(\mathrm{mg} / \mathrm{L})$ & $X_{3}$ & 12 & 300 & 100 \\
\hline
\end{tabular}

\subsection{Flotation Procedure}

The following conditioning procedure was used for all flotation tests. The flotation tests were carried out in a XFG-1600-type flotation machine (Xinghai, Shandong, China). Pure mineral particles ( $3 \mathrm{~g})$ were placed in a Plexiglas cell $(40 \mathrm{~mL})$, which was then filled with distilled water. The slurry $\mathrm{pH}$ was modified to the desired value by adding either $\mathrm{HCl}$ or $\mathrm{NaOH}$ solutions. Pulp $\mathrm{pH}$ was measured using a $\mathrm{pH}$ meter (PHS-3C). The reagents (SEG, AX, and MIBC) were added in sequence and conditioned for $2 \mathrm{~min}$ each. The operating conditions were set to $8 \mathrm{~mm}$ froth depth, $1900 \mathrm{rpm}$ impeller speed, and 30 times per minute scraping frequency. The flotation was conducted for 5 min. The products were collected, dried, and weighed. For single mineral flotation, the flotation recovery was calculated based on the dry weight of the products obtained. For mixed minerals (the ratio of $\mathrm{Cu}$ and Mo was 3:1) flotation, the flotation recovery was calculated based on $\mathrm{Cu}$ and Mo grade between the concentrates and tailings. The flow sheet and conditions of flotation tests are demonstrated in Figure 3. Both the concentrate and tailing were filtered, dried, and weighed. Concentrate $(\mathrm{Cu})$ and tailing $(\mathrm{Mo})$ were analyzed.

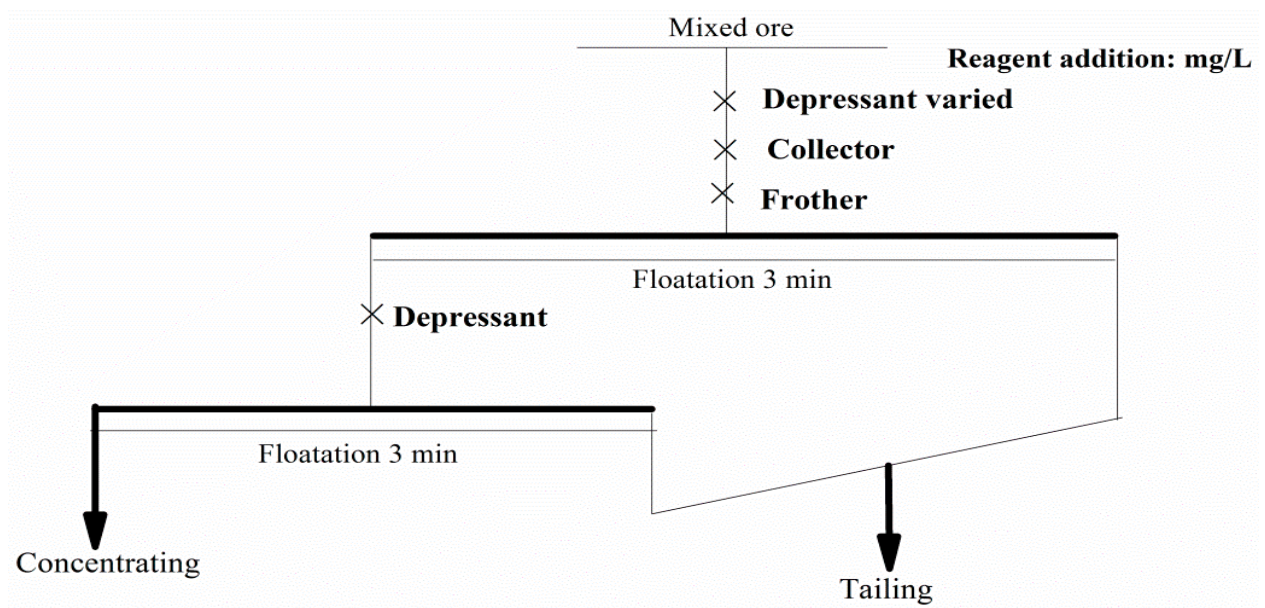

Figure 3. The beneficiation flow sheet of mixed ore experiment.

\subsection{Adsorption Experiments}

In the adsorption experiments, two grams of pure mineral particles were added to $40 \mathrm{~mL}$ distilled water in $100 \mathrm{~mL}$ beakers and SEG was added to the desired concentration (196 mg/L) at pH equal to 4 . The suspension was stirred for $3 \mathrm{~min}$ and subsequently filtered. The filtrate was centrifuged under the conditions of $25^{\circ} \mathrm{C}$ and $9000 \mathrm{rpm}$ centrifugal speeds for $20 \mathrm{~min}$. After the centrifugation was 
completed, $15 \mathrm{~mL}$ of supernatant was transferred to a clean centrifuge tube for Total Organic Carbon (TOC) test. The same procedure was used to determine the original TOC of SEG/AX without reacting with any minerals. The TOC $\left(T_{1}\right)$ of SEG remaining in the supernatant was measured using the TOC-L machine supplied by Shimadzu, Kyoto, Japan. It was assumed that the amount of TOC $\left(T_{2}\right)$ of SEG depleted from the solution had adsorbed onto the particular mineral phase. The amount of TOC for single SEG was recorded as $T_{0}$.

The method to test the adsorption density of the collector AX after adding the depressant SEG was as follows. First, two grams of pure mineral particles were added to $40 \mathrm{~mL}$ distilled water in $100 \mathrm{~mL}$ beakers and SEG was added to the desired concentration $(196 \mathrm{mg} / \mathrm{L})$ at $\mathrm{pH} 4$. The suspension was stirred for $3 \mathrm{~min}$ and subsequently filtered. Then, the filter residue was washed three times using distilled water. The filter residue was transferred to a clean beaker, $40 \mathrm{~mL}$ of distilled water was added, and the water $\mathrm{pH}$ was adjusted to 4, the collector AX was added, and stirring was applied for 3 min. Finally, the suspension was centrifuged and the TOC of AX remaining in the supernatant was measured using the TOC-L equipment.

The ultimate adsorption density of SEG on the mineral surface after adding AX was equal to the adsorption density of both SEG and AX minus the adsorption density of single AX after adding the depressant SEG. In this paper, TOC adsorption efficiency was used to measure the adsorption effect of the reagents, and the adsorption efficiency was expressed as:

$$
\varepsilon=\frac{T_{0}-T_{1}}{T_{0}} \times 100 \%
$$

\subsection{Zeta Potential Measurements}

The zeta potential of minerals treated and untreated by the flotation reagents was measured by a JS94H micro electrophoresis instrument (Shanghai Zhongchen Digital Technic Apparatus Co., Shanghai, China). The measurement was carried out at $25^{\circ} \mathrm{C}$. A $20 \mathrm{mg}$ sample was placed in a $100 \mathrm{~mL}$ beaker with $40 \mathrm{~mL}$ aqueous solutions containing $10 \mathrm{mM} \mathrm{KNO}_{3}$ as the supporting electrolyte, and the mineral suspension was conditioned with reagents over the $\mathrm{pH}$ range of 3-12 [25]. All of the samples were thoroughly equilibrated, and an average zeta potential value of at least three individual measurements was recorded.

\subsection{FT-IR Spectroscopy Experiments}

The following procedure was used for FT-IR spectroscopy experiments by a 740FT-IR instrument (Nicolet Co., Waltham, MA, USA). The untreated pure mineral particles were used as a reference spectrum. One gram of pure mineral particles was added into $30 \mathrm{~mL}$ aqueous solution with or without $197 \mathrm{mg} / \mathrm{L}$ depressant and $16 \mathrm{mg} / \mathrm{L}$ collector at $\mathrm{pH}$ 4, and ultrasonicated for $5 \mathrm{~min}$. Next, the solutions were magnetically stirred for $40 \mathrm{~min}$ and settled for another $40 \mathrm{~min}$. After filtering, the precipitate was washed three times with distilled water and then vacuum dried at $40{ }^{\circ} \mathrm{C}$. Fourier transform infrared (FT-IR) spectra of solids were recorded using a FT-IR spectrometer at room temperature $\left(25 \pm 1^{\circ} \mathrm{C}\right)$. The spectra were recorded with 30 scans at a resolution of $2 \mathrm{~cm}^{-1}$.

\section{Results and Discussion}

\subsection{Model Fittings and Statistical Analysis}

The complete experimental design matrix as suggested by Design-Expert Software and response values obtained from the experiments are presented in Table 2. According to experimental data, the following fitting polynomial Equations (2) and (3) were obtained from data fitting:

$$
\begin{gathered}
Y_{1}=84.91-9.63 X_{1}-8.01 X_{2}+1.1 X_{3}-1.42 X_{1} X_{2}+1.84 X_{1} X_{3} \\
Y_{2}=16.36+2 X_{1}-0.15 X_{2}+0.31 X_{3}-0.035 X_{2} X_{3}
\end{gathered}
$$


where $Y_{1}$ and $Y_{2}$ are the recovery for chalcopyrite and molybdenite, $X_{1}, X_{2}$, and $X_{3}$ are the coded values of the three independent variables described above. A positive sign in front of the terms indicates a synergistic effect, whereas a negative sign indicates an antagonistic effect [26].

Table 2. The partially experimental design matrix as suggested by Design-Expert Software.

\begin{tabular}{cccccc}
\hline Run & $\begin{array}{c}\text { Factor } \mathbf{1} \\
\text { A: } \mathbf{p H}\end{array}$ & $\begin{array}{c}\text { Factor 2 (mg/L) } \\
\text { B: SEG }\end{array}$ & $\begin{array}{c}\text { Factor 3 (mg/L) } \\
\text { C: } \mathbf{A X}\end{array}$ & $\begin{array}{c}\text { Response 1 (\%) } \\
\text { Chalcopyrite Recovery }\end{array}$ & $\begin{array}{c}\text { Response 2 (\%) } \\
\text { Molybdenite Recovery }\end{array}$ \\
\hline 1 & 12 & 300 & 55 & 66.21 & 21.01 \\
2 & 12 & 175 & 10 & 73.32 & 16.21 \\
3 & 7.5 & 175 & 55 & 84.76 & 22.31 \\
4 & 7.5 & 175 & 55 & 84.34 & 22.19 \\
5 & 12 & 50 & 55 & 82.98 & 29.16 \\
6 & 12 & 175 & 100 & 79.12 & 4.87 \\
7 & 7.5 & 300 & 10 & 69.98 & 12.98 \\
8 & 3 & 300 & 55 & 86.78 & 25.98 \\
9 & 7.5 & 50 & 10 & 85.98 & 22.10 \\
10 & 7.5 & 175 & 55 & 85.34 & 21.21 \\
11 & 3 & 50 & 55 & 98.89 & 21.54 \\
12 & 7.5 & 175 & 55 & 84.89 & 34.99 \\
13 & 7.5 & 175 & 55 & 85.21 & 21.01 \\
14 & 7.5 & 50 & 100 & 89.34 & 5.92 \\
15 & 3 & 175 & 10 & 95.21 & 71.16 \\
16 & 7.5 & 300 & 100 & 93.65 & \\
17 & 3 & 175 & 10 & & \\
\hline
\end{tabular}

Diagnostic plots, such as predicted versus actual values, were used to determine the adequacy of the model. The predicted values of recoveries (separated efficiency) were calculated using the regression model and compared with experimental values in Figure 4. As can be seen, the experimental results were in good correlation with the values predicted by the statistical model. Thus, this prediction model was sufficiently effective and feasible [27].

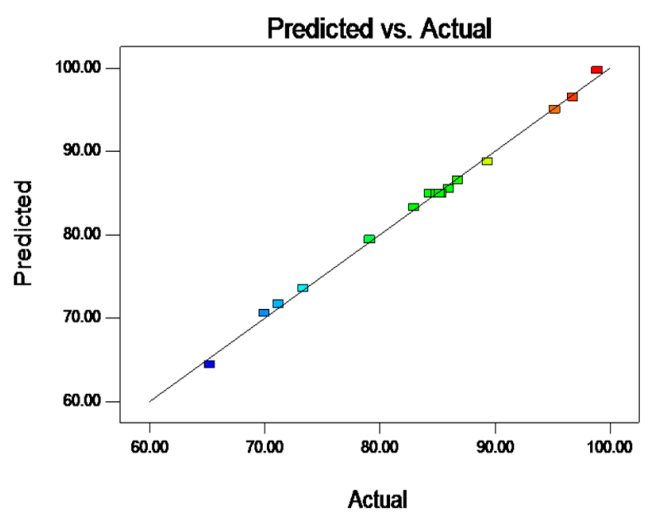

(a)

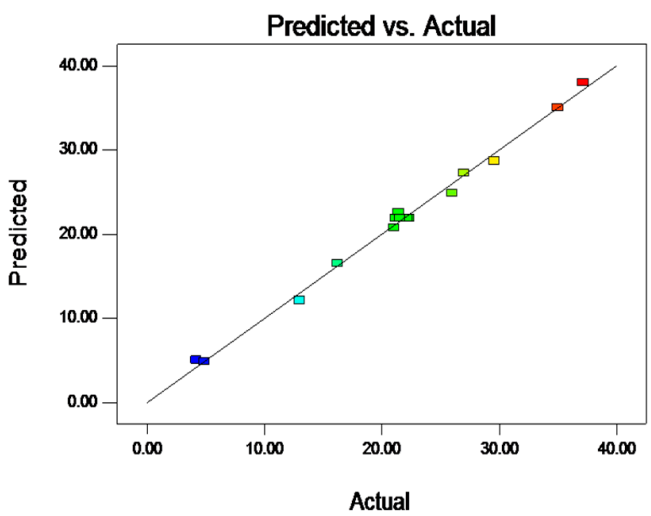

(b)

Figure 4. Design expert plot of (a) chalcopyrite and (b) molybdenite: Actual values versus predicted response by Box-Behnken design (BBD).

Furthermore, the adequacy of the obtained model to predict the separated efficiency was analyzed through analysis of variance (ANOVA). The results (chalcopyrite/molybdenite) are expressed in Table 3. The F-value was the criterion of adaptability of the model, and Prob $>F$ was the criterion of the influence degree of the factor significance [28]. The greater the $F$-value, the stronger the adaptability of the model. It was considered that an experimental factor was significant for separation efficiency if Prob $>F<0.05$ [29]. As shown in Table 3, the $F$-values of the model were 313 and 138.07 for chalcopyrite and molybdenite, respectively, indicating a high adaptability of the model. Prob $>F$ values of $X_{1}, X_{2}, X_{3}, X_{12}$, and $X_{13}$ of chalcopyrite were less than 0.05 , which means that these factors 
play an important role in the flotation of chalcopyrite. Similarly, $X_{1}, X_{2}, X_{3}$, and $X_{23}$ were important factors affecting molybdenite flotation. The Lack-of-Fit (LOF) was the criterion of the shortage of the proposed model in the prediction of the response factor [29]. The shortage of the predictive model was indistinct, as LOF was equal to 3.28/4.21 $<4.7725$. That is to say, the test method to predict the separated efficiency between chalcopyrite and molybdenite was reliable in this research. The adequate precision ratio (AP, precision criterion) was 65.21/43.73 $(>4)$, and the coefficient of variance $(\mathrm{CV}$, precision criterion) was $0.84 / 4.60 \%(<10 \%)$, proving the high accuracy of the predictive model [30-32]. The multivariate correlation coefficient $R^{2}$ equal to $0.997 / 0.994$ means that the model could explain the change of the response value to the extent of $99.7 \% / 99.4 \%$ for chalcopyrite and molybdenite, respectively. The reliability criterion $\left(R_{\mathrm{adj}}{ }^{2}-R_{\text {pred }}{ }^{2}\right)$ equal to $0.027 / 0.066<0.2$ proves the high reliability of the model [33].

To sum up, the regression equation could adequately simulate the real surface in the research area. The precision, reliability, and accuracy of the model were within the acceptable range of error. Therefore, it was noticeable that the selected model was suitable for navigating the design space.

Table 3. ANOVA for response surface quadratic model $(\mathrm{Cu} / \mathrm{Mo})$.

\begin{tabular}{cccc}
\hline Source & $\boldsymbol{F}$ Value $(\mathbf{C u} / \mathbf{M o})$ & & Prob $>\boldsymbol{F}(\mathbf{C u} / \mathbf{M o})$ \\
\hline Mode & $1313 / 138.0$ & & $<0.0001$ \\
$X_{1}$-pH & $1491 / 22.87$ & & $<0.0001 / 0.002$ \\
$X_{2}$-SEG & $1031 / 120.5$ & & $<0.0001$ \\
$X_{3}$-AX & $19.3 / 75.3$ & & $0.003 /<0.0001$ \\
$X_{12}$ & $16.1 / 1.25$ & & $0.005 / 0.32$ \\
$X_{13}$ & $27.3 / 3.13$ & & $0.001 / 0.12$ \\
$X_{23}$ & $2.39 / 14.43$ & & $0.166 / 0.006$ \\
Lack of fit $(F)$ & $3.28 / 4.21$ & Lack of fit $(\mathrm{P})$ & $0.056 / 0.030$ \\
$R^{2}$ & $0.99 / 0.99$ & $R_{\text {adj }}{ }^{2}-R_{\text {pred }}{ }^{2}$ & $0.027 / 0.066$ \\
C.V. $\%$ & $0.84 / 4.60$ & Adeq precisor $^{2}$ & $65.21 / 43.73$ \\
\hline
\end{tabular}

\subsection{Interactions among the Factors and Optimization Results}

Two-dimensional contour plots were applied to demonstrate the interactive effects of operational parameters on the recovery of chalcopyrite and molybdenite. Figure 5 shows the corresponding contour of the combined effect of $\mathrm{pH}$ and dosage of SEG, while AX was maintained at $20 \mathrm{mg} / \mathrm{L}$. From the contours, it was clear to understand the interactive effects between the two independent variables and further to decide the optimum levels.

The effects of pulp pH and the dosage of SEG in the flotation of chalcopyrite became increasingly obvious. The inhibition effect was enhanced with the increase of the dosage of SEG, exceeding $250 \mathrm{mg} / \mathrm{L}$ at the same $\mathrm{pH}$ values. The pulp $\mathrm{pH}$ was significant for chalcopyrite flotation especially at alkaline conditions caused by forming metal hydroxides such as copper hydroxide and ferric hydroxide on the surface of chalcopyrite. The metal hydroxides easily formed hydrogen bonds with water molecules while exhibiting a certain hydrophilicity on the mineral surface, resulting in the decrease of the floatability of chalcopyrite [34]. Figure 5a shows that compared with chalcopyrite, the floatability of molybdenite became much weaker after adding the SEG depressant. At $\mathrm{pH} 4$, the flotation recovery of chalcopyrite dropped from over $95 \%$ in the presence of SEG $50 \mathrm{mg} / \mathrm{L}$ to about $85 \%$ in the presence of the $300 \mathrm{mg} / \mathrm{L}$ SEG. Between $\mathrm{pH} 3$ and 7 and in the presence of SEG under $200 \mathrm{mg} / \mathrm{L}$, the recovery of chalcopyrite decreased from $95 \%$ to about $90 \%$, and stayed there at higher pHs. For molybdenite, its recovery dropped from $30 \%$ in the presence of SEG $50 \mathrm{mg} / \mathrm{L}$ to $10 \%$ in the presence of $300 \mathrm{mg} / \mathrm{L}$ SEG at pH 4. Between $\mathrm{pH} 3$ and 12 and in the presence of SEG under $100 \mathrm{mg} / \mathrm{L}$, the recovery of molybdenite was increased from $20 \%$ to about $35 \%$, and stayed there at higher $\mathrm{pH}$. In alkaline solutions, the double layer repulsion between molybdenite and bubbles was decreased gradually after the adsorption of SEG on the surface of molybdenite and probably strengthen the floatability of molybdenite [35]. 
Figure $5 \mathrm{~b}$ shows the corresponding contour of the combined effect of $\mathrm{pH}$ and dosage of $\mathrm{AX}$, while SEG was maintained at $175 \mathrm{mg} / \mathrm{L}$. The effect of AX dosage on chalcopyrite flotation was inapparent, especially under the condition of $\mathrm{pH}$ less than 10 caused by excellent natural floatability and the poor adsorption capacity of the depressant. However, the floatability of molybdenite was greatly affected by the dosage of $\mathrm{AX}$, probably due to the stronger adsorption capacity of $\mathrm{AX}$, and weakened the effect of inhibitors gradually. This was the reason why the recovery rate of molybdenite increased with dosage of AX.

Figure 5c shows the corresponding contour of the combined effect of dosage of AX and SEG, whilst $\mathrm{pH}$ was maintained at 3.4 (natural). It was proved that the recoveries of molybdenite increased with the increase in SEG concentration, while it basically had no influence on chalcopyrite flotation. Furthermore, the result also showed that the recovery difference between chalcopyrite and molybdenite was decreased gradually as the AX concentration was increased.

Based on the analysis by Design-Expert, optimization results were achieved to evaluate the optimal experimental parameters for the separation efficiency of chalcopyrite and molybdenite. Table 4 shows the optimum conditions based on a combination of all the corresponding contours. Under the optimum conditions of initial pH 4, SEG dosage $197 \mathrm{mg} / \mathrm{L}$, and AX dosage $16 \mathrm{mg} / \mathrm{L}$, the recovery of $95.82 / 9.67 \%$ for chalcopyrite/molybdenite was achieved after using $20 \mathrm{mg} / \mathrm{L} \mathrm{MIBC}$ as frother. Only a small deviation $(<2 \%)$ was exhibited between the experimental values and the predicted values. Thus, the BBD model can be used to optimize the process of separating efficiency of chalcopyrite and molybdenite.

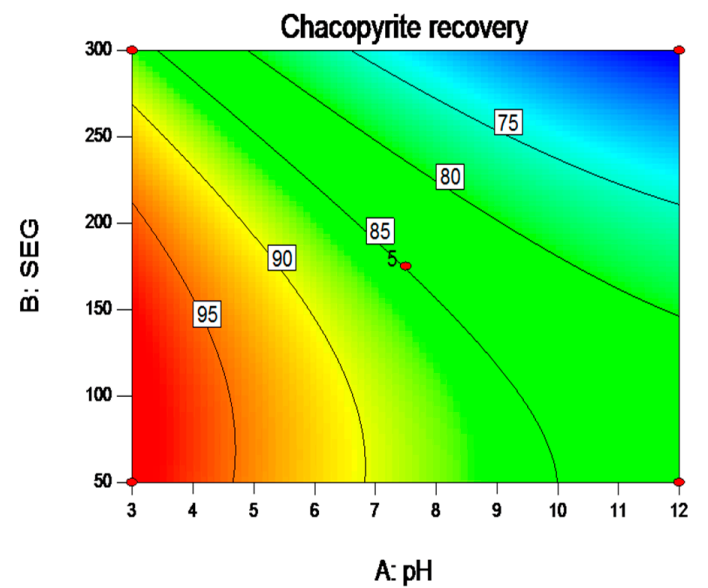

(a)

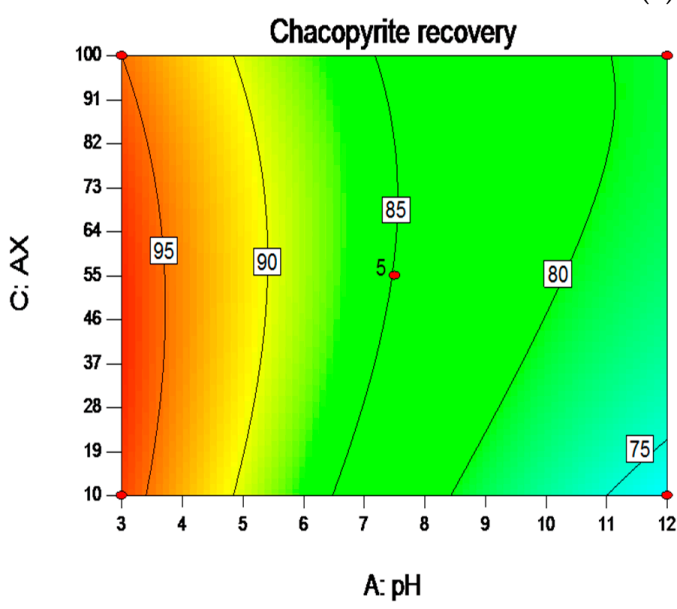

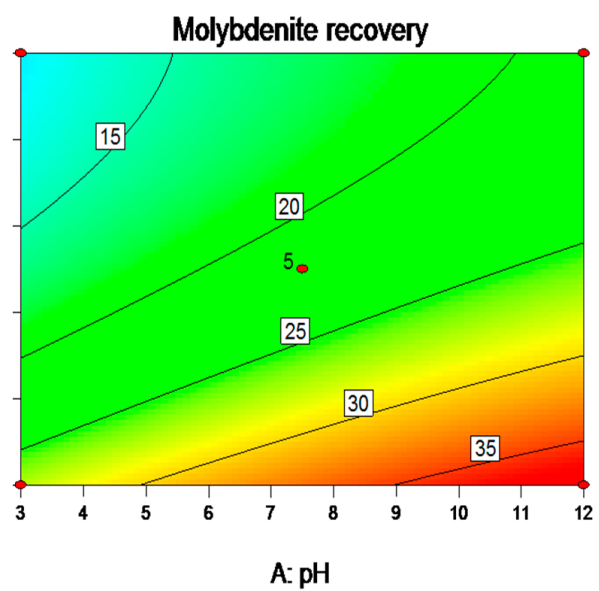

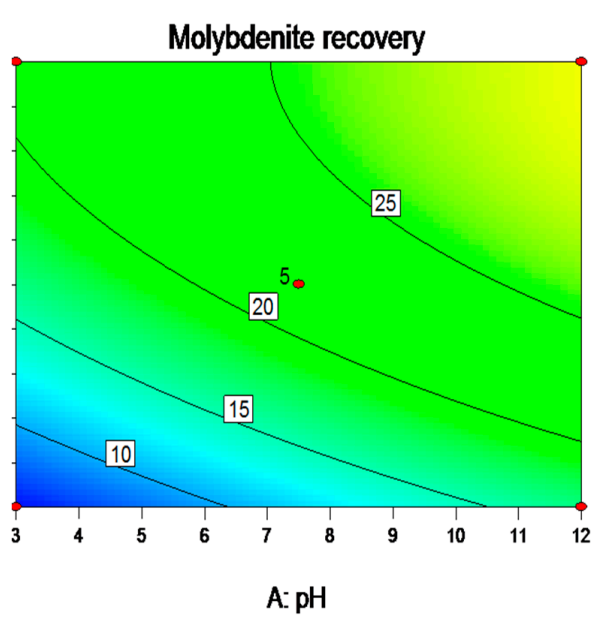

(b)

Figure 5. Cont. 

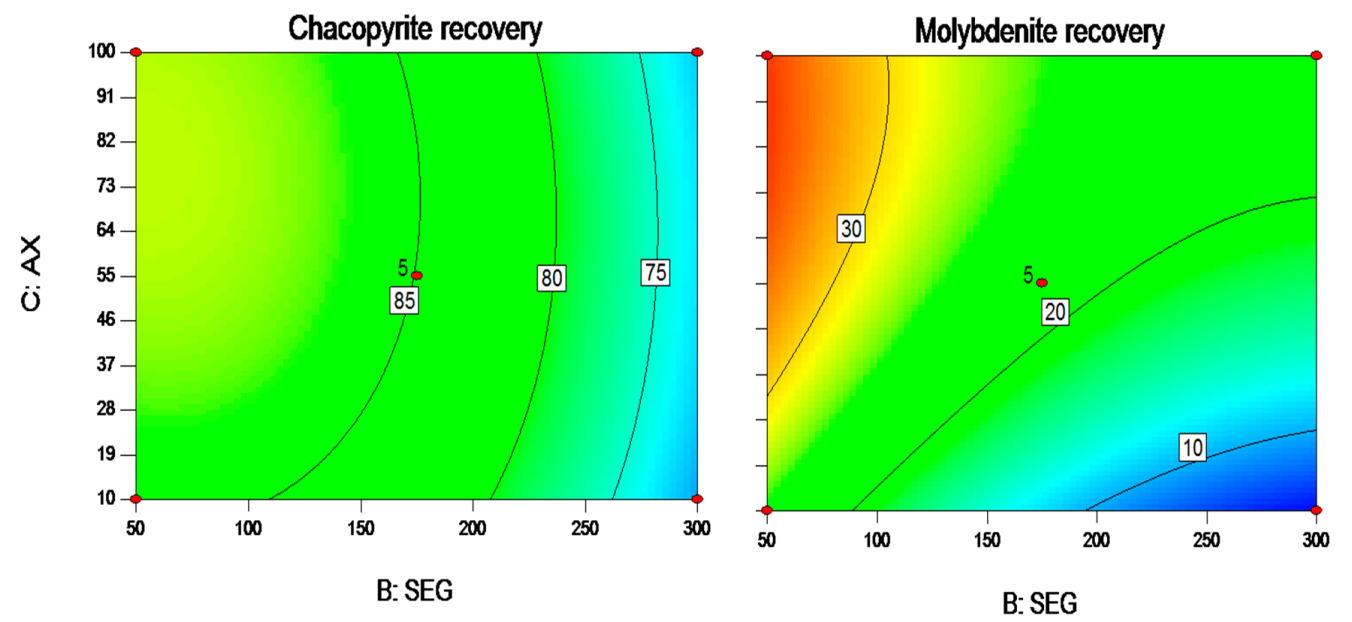

(c)

Figure 5. Response surface plots and contours for separation efficiency as a function of (a) SEG dosage and $\mathrm{pH}$ (amyl xanthate, AX: $20 \mathrm{mg} / \mathrm{L}$ ); (b) $\mathrm{pH}$ and AX dosage (SEG: $175 \mathrm{mg} / \mathrm{L}$ ); and (c) SEG dosage and AX dosage $(\mathrm{pH}=3.4)$.

Table 4. Predicted and experimental values of the responses of optimum conditions.

\begin{tabular}{ccccc}
\hline \multirow{2}{*}{ Initial pH } & \multirow{2}{*}{$\begin{array}{c}\text { SEG Dosage } \\
(\mathbf{m g} / \mathrm{L})\end{array}$} & \multirow{2}{*}{$\begin{array}{c}\text { AX Dosage } \\
(\mathbf{m g} / \mathrm{L})\end{array}$} & \multicolumn{2}{c}{ Cu/Mo Recovery (\%) } \\
\cline { 4 - 5 } & & 16.32 & Predicted Value & Experimental Value \\
\hline 4.07 & 197.38 & & $95.11 / 7.99$ & $93.21 / 6.98$ \\
\hline
\end{tabular}

\subsection{Contrast Experiments of Depressant}

As stated in the previous studies, it has been shown that either adopting a traditional depressant can achieve significant improvement in copper removal efficiency results [3-7]. However, since the purpose of this study was to evaluate the replacement of traditional depressant with SEG in the flotation separation of $\mathrm{Cu}$-Mo sulphide ores. Therefore, further tests were conducted on the flotation separation of chalcopyrite-molybdenite using different depressants through an open circuit like Figure 3. It especially needs to be emphasized that the comparison experiments were designed to analyze the flotation tailing $(\mathrm{Cu})$ after using conventional inhibitors and the flotation concentrate $(\mathrm{Cu})$ by SEG inhibitor. Figure 6 compares the results of $\mathrm{Cu}$-Mo separation obtained using the traditional depressant and the new depressant SEG. In this study, the flotation process was evaluated by defining the removal efficiency, which as introduced by Mowla [36], $\epsilon$, is defined as follows:

$$
\epsilon=\frac{C_{i}-C_{f}}{C_{i}} \times 100 \%
$$

$C_{i}$ and $C_{f}$ are the initial and final molybdenum concentrations in the chalcopyrite concentrate, respectively.

The effects of various depressants on the Mo removal efficiency and $\mathrm{Cu}$ recovery are shown in Figure 6. As seen in Figure 6, as the depressant concentration increased, the removal efficiency of Mo increased, and only a small effect on Cu recovery was observed. It could be seen that the removal efficiency of molybdenite presented similar trends, while using different depressants. Initially, the removal efficiency of molybdenite gradually increased with the increase of depressant concentration; however, the removal efficiency increased slowly when the depressant was increased to a certain concentration. The results indicated that the $\mathrm{Cu}$ recovery was affected by the higher concentration of depressant, which may be explained by the fact that strong adsorption had a negative effect on chalcopyrite flotation. Taking Mo removal efficiency and $\mathrm{Cu}$ recovery into consideration, the optimal 
concentration was $200 \mathrm{mg} / \mathrm{L}$ with SEG as depressant. All five of the depressants showed an excellent selectivity for the separation of molybdenite and chalcopyrite.

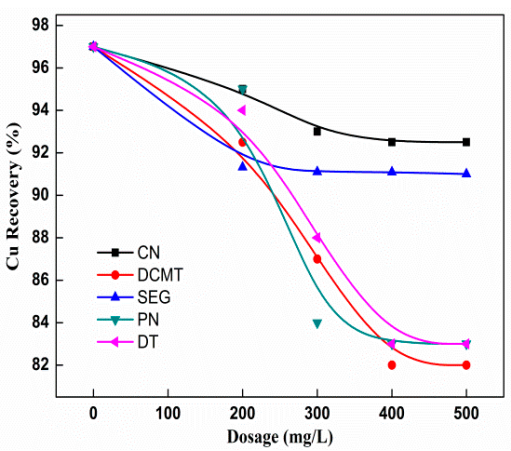

(a)

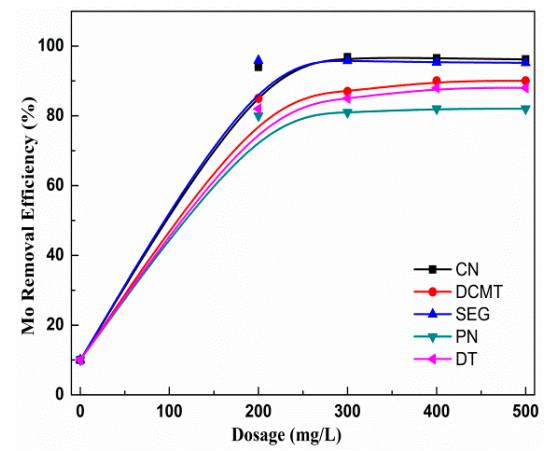

(b)

Figure 6. (a) Cu recovery versus (b) Mo removal efficiency using different depressants (CN: sodium cyanide, DCMT: disodium carboxymethyl trithiocarbonate, PN: P-Nokes reagent, DT: the main ingredient is sodium hypochlorite, SEG: seaweed glue).

\subsection{Adsorption Studies}

The adsorption behaviors of SEG and AX on chalcopyrite and molybdenite surfaces as a function of $\mathrm{pH}$ are given in Figure 7. It was proved that the adsorption efficiency of SEG on molybdenite was obviously higher than chalcopyrite, even though the adsorption capacity of chalcopyrite increased with increases of $\mathrm{pH}$ value. Satisfactory results for the adsorption efficiency of SEG on chalcopyrite and molybdenite surface were about $83 \%$ and $10 \%$, respectively, when $\mathrm{pH}$ was less than 5 . This may be related to the formation of hydrophilic metal hydroxides on the surface of chalcopyrite, especially in alkaline condition [34]. The contrast in adsorption efficiency changes of these minerals shows that the treatment of AX has little influence on the interactions between SEG and these minerals.

One interesting result was that the collector AX basically maintained a consistent adsorption efficiency on chalcopyrite and molybdenite surfaces with and without SEG throughout the experiments. This was further proof of the previous conjecture: it is likely that SEG depressed molybdenite by covering the dixanthogen resulting from adsorption of xanthate ions [25]. However, chalcopyrite still kept a good floatability in the experiments because of the low adsorption efficiency of SEG. The schematic diagram of the adsorption model is shown in Figure 8. All of the characteristics discussed above were extremely helpful for improving the selective separation efficiency between molybdenite and chalcopyrite.

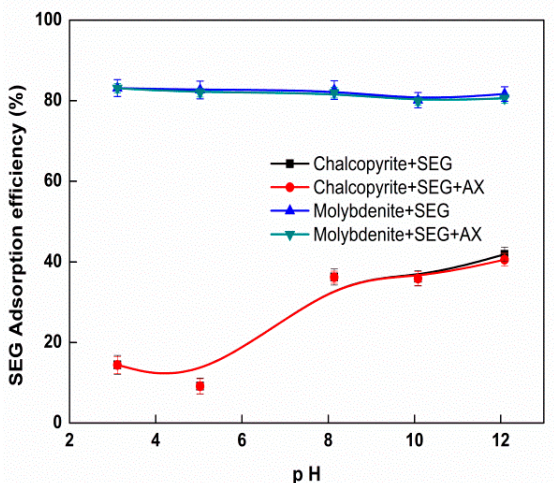

(a)

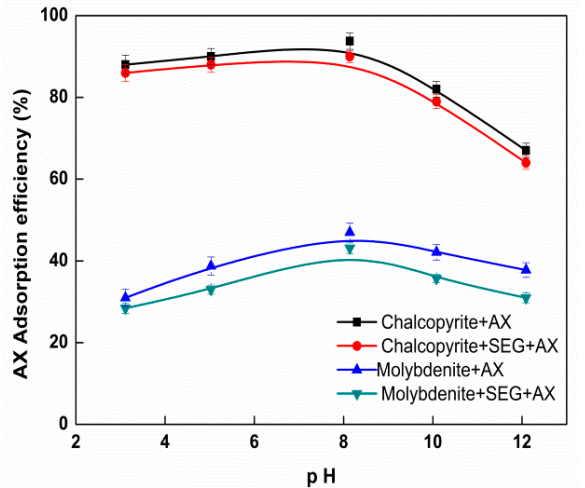

(b)

Figure 7. The adsorption efficiency of (a) SEG and (b) AX on single mineral surfaces as a function of pH (SEG: $197 \mathrm{mg} / \mathrm{L}, \mathrm{AX}: 16 \mathrm{mg} / \mathrm{L}$ ). 


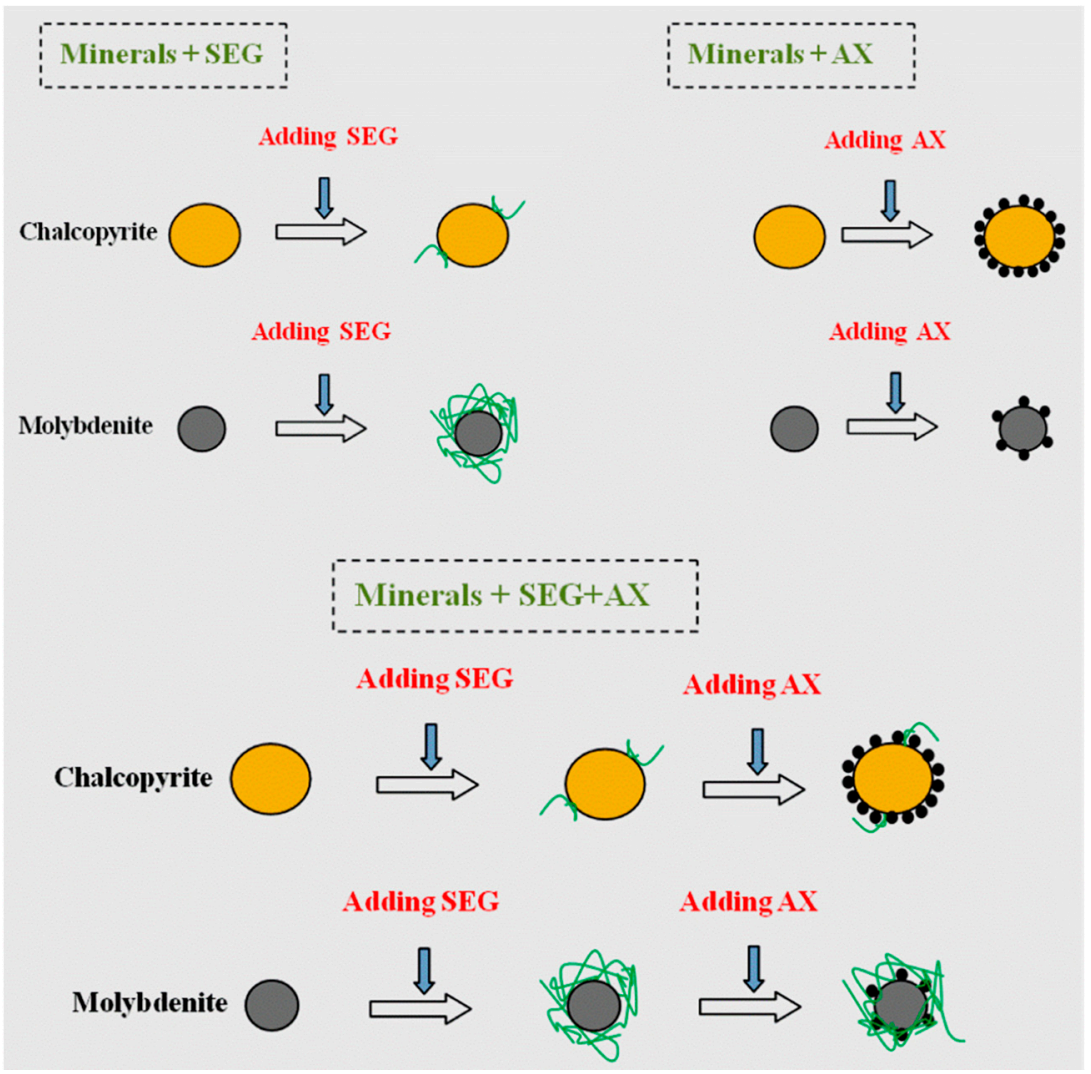

Figure 8. Schematic diagram of adsorption of chalcopyrite and molybdenite $(\mathrm{pH}=4)$.

\subsection{Zeta Potential Tests}

Figure 9a gives the zeta-potential of chalcopyrite in the absence and presence of SEG and AX under different $\mathrm{pH}$ conditions. It can be seen that the surface zeta potential of chalcopyrite in the presence of SEG did not change significantly compared with the raw ore at $\mathrm{pH}$ less than 4 . This indicated that SEG had a negligible effect on the zeta-potential of chalcopyrite, and the adsorption capacity of SEG on chalcopyrite surfaces was poor. However, the zeta potential was positively shifted with $\mathrm{pH}$ increases, meaning that the adsorption of SEG on chalcopyrite surface was gradually enhanced. After the addition of collector $\mathrm{AX}$, the zeta potential shifted negatively at $\mathrm{pH}$ less than 9 , indicating that the addition of inhibitors did not affect the adsorption of AX on the surface of chalcopyrite.

However, the zeta potential shifted positively as $\mathrm{pH}$ increased above 9 and gradually approached the surface potential of chalcopyrite in the presence of SEG alone. This probably indicated that the adsorption efficiency of the depressant SEG was strengthened while the collector AX was decreased under strong alkaline conditions.

From Figure $9 b$, the surface potential of molybdenite after adding inhibitor SEG saw a positive shift compared with the raw ore, probably caused by the chemical adsorption of SEG on the molybdenite surface. The surface zeta potential of molybdenite maintained constant after reaction with the depressant SEG throughout the range of evaluated $\mathrm{pH}$ values. After the addition of the collector $\mathrm{AX}$, the zeta potential of molybdenite changed slightly. However, the adsorption experiment results showed that the adsorption of SEG on the surface of molybdenite basically did not prevent the adsorption of the collector AX. Therefore, combined with the two experimental results verified the conjecture in flotation discussion, it can be said that the seaweed glue depresses molybdenite by covering the dixanthogen absorbed [25] on the surface resulting from the adsorption of xanthate ions. 


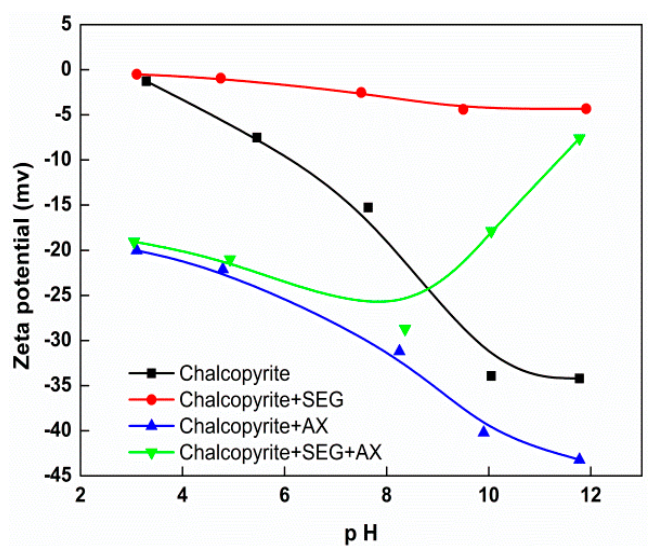

(a)

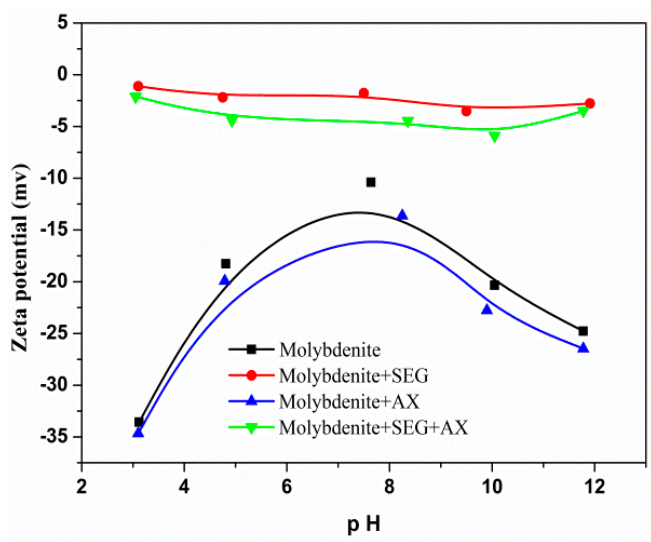

(b)

Figure 9. Zeta-potential of (a) chalcopyrite and (b) molybdenite in the absence and presence of SEG and AX under different $\mathrm{pH}$ conditions (SEG: $197 \mathrm{mg} / \mathrm{L}, \mathrm{AX}: 16 \mathrm{mg} / \mathrm{L}$ ).

\subsection{FT-IR Spectra Analysis}

In order to study the depression mechanism of SEG, the FT-IR spectra of the minerals before and after interacting with SEG were determined, and the results are shown in Figure 10a,b.

The FT-IR spectrum of molybdenite interacting with SEG (Figure 10b,c) show the characteristic bands of molybdenite near $3415 \mathrm{~cm}^{-1}, 1643 \mathrm{~cm}^{-1}, 1423 \mathrm{~cm}^{-1}$, respectively due to $-\mathrm{OH}$ stretching vibration, $-\mathrm{COO}-$ stretching vibration, indicating that a strong adsorption of SEG on the molybdenite surface has occurred [37-39]. The adsorption of -OH and -COO- groups on the molybdenite surface illustrates that SEG adsorbs on molybdenite surface, which contains these functional groups in its molecular structure.

Figure 10b also shows the FT-IR spectrum of chalcopyrite after interacting with SEG. It is clear from Figure 10b that SEG has a negligible effect on the spectrum of chalcopyrite. After interacting with SEG, the characteristic adsorption bands of chalcopyrite shared no obvious changes, and no new bands appeared. These results illustrate that the SEG depressant cannot interfere with the FT-IR spectrum of chalcopyrite and the adsorption capacity of SEG on chalcopyrite surface is poor, which explains the flotation and adsorption results.

It is tenable to conclude that the depressant SEG adsorbs more strongly on the molybdenite surface than on the chalcopyrite surface, and the chemical adsorption process may dominate the interaction of depressant with molybdenite, which are confirmed by adsorption studies and FT-IR analysis, respectively. This may be the reason why SEG has high depression selectivity for molybdenite and little effect on chalcopyrite flotation.

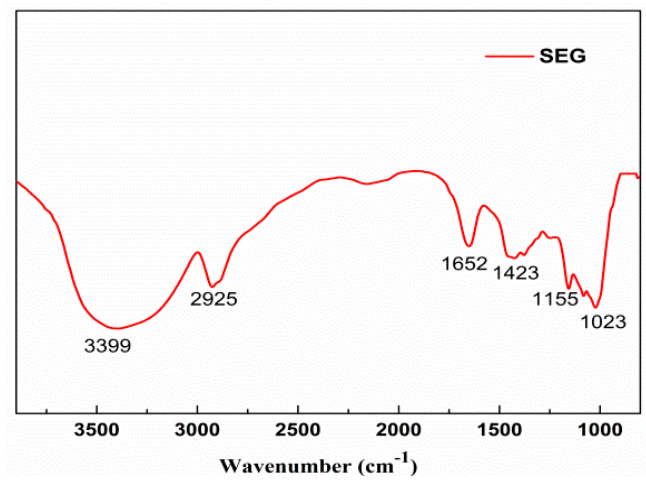

(a)

Figure 10. Cont. 


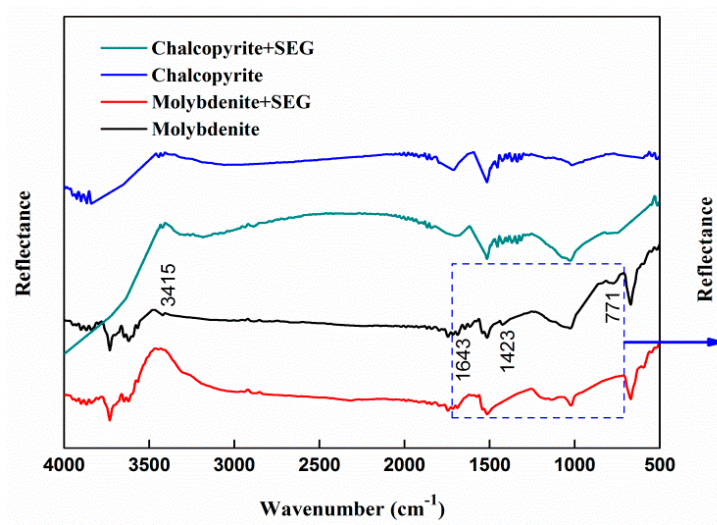

(b)

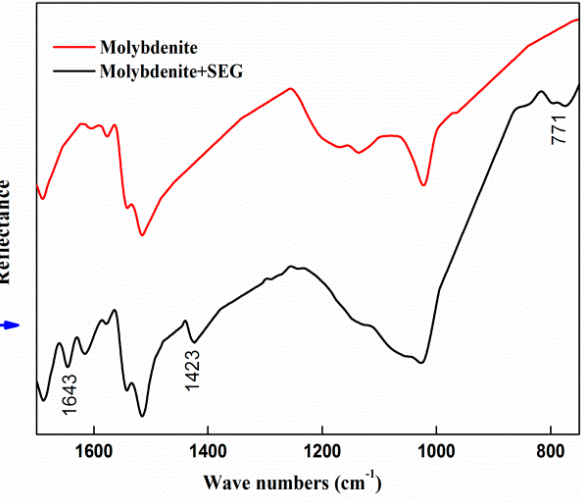

(c)

Figure 10. FT-IR spectra of (a) SEG and (b) these two minerals before and after interacting with the SEG system and (c) the amplified spectrum of molybdenite from 830 to $1700 \mathrm{~cm}^{-1}$.

\section{Conclusions}

In this work, flotation separation of chalcopyrite from molybdenite was studied using seaweed glue (SEG) as a depressant. Response surface methodology with a Box-Behnken Design suggested the optimal reagent schedule: $\mathrm{pH}$ 4, depressant seaweed glue $197 \mathrm{mg} / \mathrm{L}$, collector amyl xanthate $16 \mathrm{mg} / \mathrm{L}$ and frother (methyl isobutyl carbinol) $20 \mathrm{mg} / \mathrm{L}$, and selective separation of chalcopyrite and molybdenite was achieved by flotation. Comparison of SEG and traditional depressants indicated that the SEG could achieve similar separation efficiency, and exhibited the advantages of environmental compatibility and economic adaptability. The results of FT-IR spectrum measurements indicated that the SEG depressant could adsorb more strongly on the molybdenite surface than chalcopyrite, and the chemical adsorption process may dominate the interaction of SEG with molybdenite.

Although the tests were performed with the use of single minerals, the flotation results for molybdenite and chalcopyrite indicate that SEG could be used as a selective depressant under acidic $\mathrm{pH}$. It is shown that SEG is as effective depressant of $\mathrm{Cu} / \mathrm{Mo}$ separation as cyanide.

Acknowledgments: The authors acknowledge the support of the National Natural Science Foundation of China (No. 51374249), the National Key Technology R\&D Program (No. 2015BAB12B02) and the Science and Technology Planning Project Guangdong Province, China (No. 2013B090800016).

Author Contributions: Guohua Gu, Zhixiang Chen and Shuangke Li conceived and designed the experiments; Zhixiang Chen and Shuangke Li performed the experiments and analyzed the data; Chongqing Wang and Renfeng Zhu contributed reagents and materials; Zhixiang Chen, Guohua Gu and Chongqing Wang wrote the paper.

Conflicts of Interest: The authors declare no conflict of interest.

\section{References}

1. Ansari, A.; Pawlik, M. Floatability of chalcopyrite and molybdenite in the presence of lignosulfonates. Part II. Hallimond tube flotation. Miner. Eng. 2007, 20, 609-616. [CrossRef]

2. Feng, B.; Feng, Q.M.; Lu, Y.P. A novel method to limit the detrimental effect of serpentine on the flotation of pentlandite. Int. J. Miner. Process. 2012, 114, 11-13. [CrossRef]

3. Yin, Z.; Sun, W.; Hu, Y. Utilization of acetic acid-[(hydrazinylthioxomethyl)thio]-sodium as a novel selective depressant for chalcopyrite in the flotation separation of molybdenite. Sep. Purif. Technol. 2017, 179, $248-256$. [CrossRef]

4. Li, M.Y.; Wei, D.; Cui, B. Flotation Behavior of Chalcopyrite and Molybdenite in the Presence of 2,3-Disulfanylbutanedioic Acid. J. Northeast. Univ. Nat. Sci. 2015, 36, 1020-1024.

5. Peng, H.; Wu, D.; Abdalla, M. Study of the Effect of Sodium Sulfide as a Selective Depressor in the Separation of Chalcopyrite and Molybdenite. Minerals 2017, 7, 51. [CrossRef] 
6. Yin, Z.; Sun, W.; Liu, J. Investigation into the flotation response of refractory molybdenum ore to depressant mixtures: A case study. Int. J. Min. Sci. Technol. 2016, 26, 1089-1094. [CrossRef]

7. Sun, W.; Yin, Z.; Hu, Y. Evaluation of the replacement of $\mathrm{NaCN}$ with depressant mixtures in the separation of copper-molybdenum sulphide ore by flotation. Sep. Purif. Technol. 2017, 173, 9-16.

8. Lin, Q.Q.; Gu, G.H.; Wang, H. Recovery of molybdenum and copper from porphyry ore via iso-flotability flotation. Trans. Nonferrous Met. Soc. China 2017, 27, 2260-2271. [CrossRef]

9. Ansari, A.; Pawlik, M. Floatability of chalcopyrite and molybdenite in the presence of lignosulfonates. Part I. Adsorption studies. Miner. Eng. 2007, 20, 600-608. [CrossRef]

10. Chen, H.T.; Ravishankar, S.A.; Farinato, R.S. Rational polymer design for solid-liquid separations in mineral processing applications. Int. J. Miner. Process. 2003, 72, 75-86. [CrossRef]

11. Gustafsson, J.O.; Lannefors, C.J. Polyquaternary Polymer as a Depressant in a Method for Froth Flotation of Potash Ores. WO/2014/095797, 26 June 2014.

12. Pearse, M.J. Historical use and future development of chemicals for solid-liquid separation in the mineral processing industry. Miner. Eng. 2003, 16, 103-108. [CrossRef]

13. Andreeva, N.; Ishizaki, T.; Baroch, P. Creating Biointerface on Polymer by Plasma-Initiated Graft Polymerization. Trans. Mater. Res. Soc. Jpn. 2011, 36, 549-552. [CrossRef]

14. Badiger, H.; Shukla, S.; Kalyani, S. Characterization of sodium alginate membrane crosslinked with glutaraldehyde in pervaporation separation. J. Appl. Polym. Sci. 2014, 131, 209-219.

15. Rhim, J.W. Physical and mechanical properties of water resistant sodium alginate films. LWT Food Sci. Technol. 2004, 37, 323-330. [CrossRef]

16. Harnsilawat, T.; Pongsawatmanit, R.; Mcclements, D.J. Characterization of $\beta$-lactoglobulin-sodium alginate interactions in aqueous solutions: A calorimetry, light scattering, electrophoretic mobility and solubility study. Food Hydrocoll. 2006, 20, 577-585. [CrossRef]

17. Vikartovská, A.; Bučko, M.; Mislovičová, D. Improvement of the stability of glucose oxidase via, encapsulation in sodium alginate-cellulose sulfate-poly(methylene-co-guanidine) capsules. Enzym. Microb. Technol. 2007, 41, 748-755. [CrossRef]

18. Chen, W.; Feng, Q.; Zhang, G. The effect of sodium alginate on the flotation separation of scheelite from calcite and fluorite. Miner. Eng. 2017, 113, 1-7. [CrossRef]

19. Sasaki, T.; Machida, I.; Ishiwata, S. Macromolecular ion flotation of $\mathrm{Fe}^{3+}, \mathrm{Cu}^{2+}$, and $\mathrm{Ni}^{2+}$ ions by combined use of macromolecular anions and cationic surfactant. Bull. Chem. Soc. Jpn. 1982, 55, 3109-3112. [CrossRef]

20. Treenate, P.; Monvisade, P. In vitro drug release profiles of $\mathrm{pH}$-sensitive hydro-xyethylacryl chitosan/sodium alginate hydrogels using paracetamol as a soluble model drug. Int. J. Biol. Macromol. 2017, 99, 71-78. [CrossRef] [PubMed]

21. Harmer, S.L.; Thomas, J.E.; Fornasiero, D.; Gerson, A.R. The evolution of surface layers formed during chalcopyrite leaching. Geochim. Cosmochim. 2006, 70, 4392-4402. [CrossRef]

22. Mikhlin, Y.L.; Tomashevich, Y.V.; Asanov, I.P.; Okotrub, A.V.; Varnek, V.A.; Vyalikh, D.V. Spectroscopic and electrochemical characterization of the surface layers of chalcopyrite $\left(\mathrm{CuFeS}_{2}\right)$ reacted in acidic solutions. Appl. Surf. Sci. 2004, 225, 395-409. [CrossRef]

23. Triffett, B.; Veloo, C.; Adair, B.J.I. An investigation of the factors affecting the recovery of molybdenite in the Kennecott Utah Copper bulk flotation circuit. Miner. Eng. 2008, 21, 832-840. [CrossRef]

24. Zhang, M. Study on reagent-making of P-nokes. China Mol. Ind. 2002, 38, 28-36.

25. Kondrat'ev, S.A.; Burdakova, E.A.; Konovalov, I.A. Collectability of physically adsorbed xanthate ion-dixanthogen associates. J. Min. Sci. 2016, 52, 541-550. [CrossRef]

26. Song, M.M.; Branfordwhite, C.; Nie, H.L. Optimization of adsorption conditions of BSA on thermosensitive magnetic composite particles using response surface methodology. Colloids Surf. B Biointerfaces 2011, 84, 477-483. [CrossRef] [PubMed]

27. Salarian, A.A.; Hami, Z.; Mirzaei, N. N-doped $\mathrm{TiO}_{2}$, nanosheets for photocatalytic degradation and mineralization of diazinon under simulated solar irradiation: Optimization and modeling using a response surface methodology. J. Mol. Liq. 2016, 22, 183-191. [CrossRef]

28. Gelman, A. Analysis of variance. Qual. Contr. Appl. Stat. 2005, 20, 295-300.

29. Tybout, A.; Sternthal, B.; Keppel, G.; Verducci, J.; Meyers-Levy, J.; Barnes, J.; Maxwell, S.; Allenby, G.; Gupta, S.; Steenkamp, J.B.; et al. Analysis of Variance. J. Consum. Psychol. 2016, 10, 5-35. 
30. Shaykh, Z.M.; Zinatizadeh, A.A.L. Statistical modeling of photocatalytic degradation of synthetic amoxicillin wastewater (SAW) in an immobilized $\mathrm{TiO}_{2}$ photocatalytic reactor using response surface methodology (RSM). J. Taiwan Inst. Chem. Eng. 2014, 45, 1717-1726. [CrossRef]

31. Schenone, A.V.; Conte, L.O.; Botta, M.A.; Alfano, O.M. Modeling and optimization of photo-Fenton degradation of 2,4-D using ferrioxalate complex and response surface methodology (RSM). Environ. Manag. 2015, 155, 177-183. [CrossRef] [PubMed]

32. Fayazi, M.; Afzali, D.; Taher, M.A.; Mostafavi, A.; Gupta, V.K. Removal of Safranin dye from aqueous solution using magnetic mesoporous clay: Optimization study. J. Mol. Liq. 2015, 212, 675-685. [CrossRef]

33. Eslami, A.; Asadi, A.; Meserghani, M.; Bahrami, H. Optimization of sonochemical degradation of amoxicillin by sulfate radicals in aqueous solution using response surface methodology (RSM). J. Mol. Liq. 2016, 222, 739-744. [CrossRef]

34. Senior, G.D.; Trahar, W.J. The influence of metal hydroxides and collector on the flotation of chalcopyrite. Int. J. Miner. Process. 1991, 33, 321-341. [CrossRef]

35. Chulhyun, P.; Hoseok, J. The Effect of Sodium Silicate as $\mathrm{pH}$ Modifier and Depressant in the Froth Flotation of Molybdenite Ores. Mater. Trans. 2010, 51, 1367-1369.

36. Mowla, D.; Karimi, G.; Ostadnezhad, K. Removal of hematite from silica and ore by reverse flotation technique. Sep. Purif. Technol. 2008, 58, 419-423. [CrossRef]

37. Zou, Y.R. Studies on Effect of Anionic Starch on the Floatability of Aluminum-Silicon Minerals and Its Mechanism. Master's Thesis, Central South University, Changsha, China, 2008.

38. Bellamy, L.J. Infrared spectroscopy of complex molecules. In The Infra-Red Spectra of Complex Molecules; Science Press: Beijing, China, 1980; pp. 123-126.

39. Rath, R.K.; Subramanian, S.; Pradeepy, T. Surface chemical studies on pyrite in the presence of polysaccharide-Based flotation depressants. J. Colloid Interface Sci. 2000, 229, 82-91. [CrossRef] [PubMed]

(C) 2018 by the authors. Licensee MDPI, Basel, Switzerland. This article is an open access article distributed under the terms and conditions of the Creative Commons Attribution (CC BY) license (http://creativecommons.org/licenses/by/4.0/). 